\title{
A positively charged surface patch on the pestivirus NS3 protease module plays an important role in modulating NS3 helicase activity and virus production
}

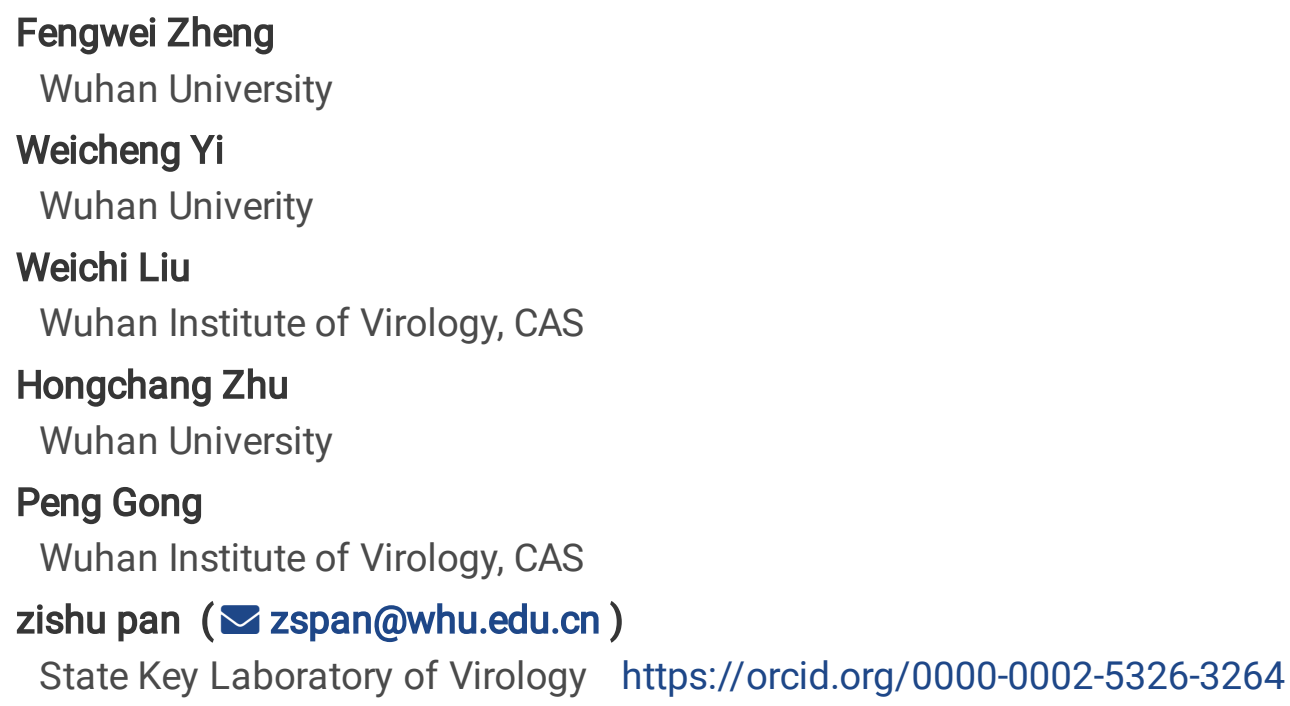

\section{Research Article}

Keywords: Pestivirus, classical swine fever virus, nonstructural protein NS3, helicase, protease

Posted Date: March 24th, 2021

DOI: https://doi.org/10.21203/rs.3.rs-223449/v1

License: @ (i) This work is licensed under a Creative Commons Attribution 4.0 International License. Read Full License

Version of Record: A version of this preprint was published at Archives of Virology on March 31st, 2021. See the published version at https://doi.org/10.1007/s00705-021-05055-5. 


\section{Abstract}

Pestivirus nonstructural protein 3 (NS3) is a multifunctional protein with protease and helicase activities that are essential for the virus replication. In this study, we used a combination of biochemical and genetic approaches to investigate the relationship between the positively charged patch on protease module and NS3 function. The surface patch was composed of four basic residues R50, K74 and K94 in NS3 protease domain and H24 in the structurally integrated cofactor NS4A PCS. Single residue or simultaneous four-residue substitution in the patch to alanine or aspartic acid hardly affect ATPase activity. However, the single R50, K94 or H24 residue or simultaneous four-residue substitution resulted in the apparent changes of the helicase activity and RNA-binding ability of NS3. When these mutations were introduced into a classical swine fever virus (CSFV) cDNA clone, the single K94 residue or simultaneous four-residue substitution (Qua_A or Qua_D) impaired the infectious virus production. Furthermore, the replication efficiency of the CSFV variants was partially correlated to the helicase activity of NS3 in vitro. Our results suggest that the conserved positively charged patch on the NS3 plays an important role in modulating the NS3 helicase activity in vitro and CSFV production.

\section{Introduction}

The Pestiviruses are causative agents of economically important livestock diseases [10, 15, 21, 37]. Members of the genus Pestivirus mainly include classical swine fever virus (CSFV), bovine viral diarrhea virus (BVDV) and border disease virus (BDV). The Pestivirus genome consists of a single, positive-stranded RNA of approximately $12.3 \mathrm{~kb}$, with one open reading frame (ORF) flanked by the $5 \rrbracket$ untranslated region (UTR) and a $3 \rrbracket$ UTR. The ORF encodes a polyprotein of approximately 4,000 amino acids $[2,8,25]$. The polyprotein is co- and post-translationally processed into 12 mature proteins by viral and host proteases $[5,14,16,17]$, including four structural proteins $C, E^{\text {rns }}, E 1$ and $E 2[38,41]$ and eight nonstructural proteins $N^{\text {pro }}, \mathrm{p} 7, \mathrm{NS} 2, \mathrm{NS} 3, \mathrm{NS} 4 \mathrm{~A}, \mathrm{NS} 4 \mathrm{~B}$, NS5A and NS5B $[12,18,27,40]$.

NS3 harbors serine protease and RNA helicase/nucleotide triphosphatase (NTPase) activities that are essential for virus replication $[13,27,36,42,43]$. Circumstantial evidences suggested that the protease and helicase/NTPase domains of NS3 were functionally interdependent $[26,29]$. NS3 protease activity requires NS4A ${ }^{\text {PCS }}$ as the structurally integrated cofactor $[36,49]$. In HCV, the NS3 protease domain enhanced its helicase activity $[3,4]$. The HCV NS3 helicase activity was modulated by NS5B, an RNA-dependent RNA polymerase (RdRP) and the protease domain was required for NS3 and NS5B interaction $[1,48]$. In CSFV, the truncated NS3 protein (NS3Hel) containing only helicase domain exhibited similar NTPase and significantly decreased helicase activity compared to the fulllength NS3 (NS3fl) [33, 39, 42,43], thereby further demonstrating that the protease and helicase domains of NS3 have functionally coupled. However, the exact mechanism for the intramolecular regulation needs to be further addressed.

Our previous study revealed an intramolecular protease-helicase interface with a positive-charged groove in Pestivirus NS3 structure. Four basic residues (R50, K74 and K94 in NS3 and H24 in NS4A ${ }^{\mathrm{PCS}}$ ) in the protease part of the groove formed a positively charged surface patch, which maybe coordinate with the helicase part of the groove to modulate RNA-binding ability and helicase activity of NS3 [49]. In this study, we further investigated the relationship between this positively charged surface patch and the NS3 function. Our data suggested that in this natural protease-helicase fusion protein, the positively charged surface patch of NS3 plays an important role in modulating NS3 helicase activity and infectious virus production. 


\section{Materials And Methods}

\section{Plasmid construction}

To prepare the wild-type (WT) NS3 and its mutated proteins, two sets of NS3 constructs containing single or simultaneous substitution in the four basic residues (R50, K74 and K94 in protease domain and H24 in NS4A ${ }^{\text {PCS }}$ ) in the positively charged surface patch to alanine or aspartic acid (Fig. 1A) were generated by using a NS3 expression plasmid (pET28a-NS3 ${ }_{S 163 A} / N_{S 4}{ }^{P C S}$ ) as a template via QuickChange mutagenesis method $[49,50]$. The variants generated by mutating the basic residue to alanine (A) or aspartic acid (D) were clustered into Set 1 or Set 2, respectively. When the four basic residues were simultaneously substituted with alanine or aspartic acid, the variant was correspondingly named as Quad_A (Quadruple_A) or Quad_D (Quadruple_D). A helicase-only construct (NS3Hel, residues 204 to 683) and the variant harboring K232A mutation in NS3 to abolish its ATPase and helicase activities were used as a negative control. We also introduced the mutations of two sets into the fulllength CSFV infectious clone [20] as previously described [45] to investigate the effect of the basic residue substitution on infectious virus production. All variants were confirmed by sequencing.

\section{Protein expression and purification}

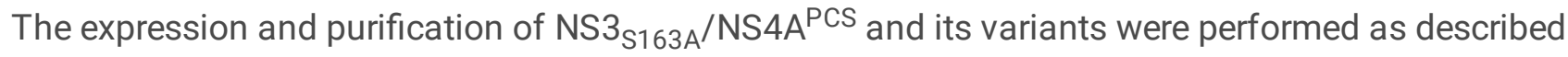
previously $[22,49]$. Briefly, the expression plasmids were transformed into $E$. coli BL21-CodonPlus (DE3)-RIL strain and then the bacteria were cultured at $37^{\circ} \mathrm{C}$ in terrific broth (TB) medium containing $50 \mu \mathrm{g} / \mathrm{ml}$ of kanamycin and $25 \mu \mathrm{g} / \mathrm{ml}$ of chloramphenicol. When the optical density at $600 \mathrm{~nm}\left(\mathrm{OD}_{600}\right)$ of the culture reached 0.8 , Isopropyl- $\beta$ D-1-thiogalactopyranoside (IPTG) was added to a final concentration of $0.5 \mathrm{mM}$. After an additional incubation at $25^{\circ} \mathrm{C}$ for $4 \mathrm{~h}$, the cells were harvested for subsequent experiments.

The harvested cells were resuspended in a lysis buffer (150 mM Na $\mathrm{SO}_{4}, 50 \mathrm{mM}$ Tris [pH 8.0], 10 mM imidazole, $0.02 \%$ [wt/vol] $\mathrm{NaN}_{3}, 20 \%$ [vol/vol] glycerol) and then lysed by an AH-2010 homogenizer (ATS Engineering Ltd.) at $14,500 \mathrm{lb} / \mathrm{in}^{2}$. After centrifugation, the clarified lysate was loaded onto a HisTrap HP column (GE Healthcare) and the target protein was eluted with an elution buffer (300 mM imidazole, $50 \mathrm{mM}$ Tris [pH 8.0], $150 \mathrm{mM} \mathrm{Na}_{2} \mathrm{SO}_{4}, 20 \%$ [vol/vol] glycerol and $0.02 \%$ [wt/vol] $\mathrm{NaN}_{3}$ ). The protein fractions were pooled, concentrated and run over a ENrich SEC 650 (Bio-Rad) equilibrated with $150 \mathrm{mM} \mathrm{NaCl}, 5 \mathrm{mM}$ Tris 7.5, 10\% (vol/vol) glycerol and 0.02\% (wt/vol) $\mathrm{NaN}_{3}$. The concentrated protein was flash frozen in liquid nitrogen and stored as aliquots at $-80^{\circ} \mathrm{C}$. The protein concentration was determined by the Bradford method [6, 35].

\section{ATPase assay}

The ATPase activity was measured using a malachite green-based method as previously described $[39,43,49]$. Briefly, the $90-\mu \mathrm{l}$ reaction mixture except for the ATP substrate was incubated at $37^{\circ} \mathrm{C}$ for $5 \mathrm{~min}$. The reaction was initiated by addition of a $10-\mu$ ATP solution to yield a final reaction mixture containing $10 \mathrm{nM} \mathrm{NS3,50} \mathrm{mM} \mathrm{Tris} \mathrm{(pH}$ 7.5), $2.5 \mathrm{mM} \mathrm{MgCl}_{2}, 50 \mathrm{mM} \mathrm{NaCl}, 5$ to $500 \mu \mathrm{M}$ ATP. After an additional incubation at $37^{\circ} \mathrm{C}$ for $15 \mathrm{~min}$, the malachite green mixture (water/0.081\% [wt/vol] malachite green/5.7\% [wt/vol] ammonium molybdate in $6 \mathrm{M} \mathrm{HCl}$ ratio $=3: 2: 1$ [vol: vol: vol]) was added and the absorbance was immediately measured at $630 \mathrm{~nm}$ on a Multiskan MK3 microplate reader (Thermo Fisher Scientific). Initial ATPase catalytic rates were determined based on the slope of the initial absorbance change and the reference standard curve of absorbance versus phosphate 
concentration determined independently. The observed ATP hydrolysis rates at various ATP concentrations were fitted to Michaelis-Menten kinetics to yield the ATPase parameters ( $K_{M}$ app and $\left.k_{c a t}\right)$.

\section{Helicase assay}

A helicase unwinding pssRNA substrate T40:R20 was prepared by annealing the template strand (T40, 5'GGGCCAAUCAUGCAUACGAGAAUGAACUAACCU-CGUAUAC-3') and the release strand (R20, 5'-

UAUCUCGUAUGCAUGAUUGG-3') labeled with a 3'-6-TAMRASE (6-carboxy-tetramethylrhodamine N-succinimidyl ester) [49]. A typical 20- $\mu$ l unwinding reaction mixture contains $8 U$ of RNasin (RiboLock; Thermo Scientific), 50 $\mathrm{mM}$ morpholinepropanesulfonic acid (MOPS)- $\mathrm{NaOH}$ (pH 7.0), $5 \mathrm{mM} \mathrm{ATP,} 2.5 \mathrm{mM} \mathrm{MgCl} 2,1 \mathrm{mM}$ dithiothreitol (DTT), $0.5 \%$ Tween 20, $0.1 \mathrm{mg} / \mathrm{ml}$ of bovine serum albumin, $10 \mathrm{nM} \mathrm{T40:R20} \mathrm{(according} \mathrm{to} \mathrm{the} \mathrm{concentration} \mathrm{of} \mathrm{the} \mathrm{R20),}$ $100 \mathrm{nM}$ unlabeled release strand (competitive strand) and $25 \mathrm{nM}$ NS3 (protein/pssRNA molar ratio = 2.5:1). The unwinding reaction proceeded at $37^{\circ} \mathrm{C}$ for $30 \mathrm{~min}$ and was then terminated by addition of $2.2 \mu \mathrm{l}$ of a $10 \times$ loading buffer (50 mM Tris [pH 7.5], 50 mM EDTA, 1\% [wt/vol] SDS, 50\% [vol/vol] glycerol, 0.1\% [wt/vol] xylene cyanol). RNAs in the quenched reaction mixtures were resolved by $12 \%$ nondenaturing polyacrylamide gel electrophoresis. The fluorescent signal of 6-TAMRASE-labeled R20 was detected using a Molecular Imager PharosFX ${ }^{\mathrm{TM}}$ Plus System (Bio-Rad) with an excitation wavelength of $532 \mathrm{~nm}$ and a $605 \mathrm{~nm}$ emission filter. The band intensities were quantified by ImageJ (http://imagej.nih.gov/ij) and the unwound percentages were calculated based on the intensity fraction of the released R20. Each unwinding reaction was independently performed four times.

\section{Fluorescence polarization (FP) -based RNA binding assay}

To determine the RNA-binding ability of NS3 and its variants, we designed the pssRNA-2 by annealing the T40 (mentioned above) and a 33-mer release strand (R33, 5'-UCCACCAAUCAAGUA-UCUCGUAUGCAUGAUUGG-3') labeled with a 5'-FAM for RNA binding assay. A FP-based RNA binding assay was used to estimate the affinity of each protein for RNA as previously described [28, 31]. Reactions were performed in a 96-well plate (Corning; Flat Bottom, Non-Binding Surface, Black Polystyrene). For each reaction, a total $72-\mu$ reaction buffer mixture was incubated at $37^{\circ} \mathrm{C}$ for 5 min and the reaction was initiated by adding NS3 to make the final reaction mixture containing 10 nM 5'-FAM labeled pssRNA-2, 50 mM MOPS-NaOH (pH 7.0), 2.5 mM MgCl 2,50 mM NaCl, 1 to 1000 nM NS3 (the molar ratio of NS3:pssRNA-2 is $0.1: 1$ to $100: 1$ ). After incubation at $37^{\circ} \mathrm{C}$ for 30 min, polarization was monitored using a Cytation 3 Cell Imaging Multi-Mode Reader (Bio Tek) by exciting at $485 \mathrm{~nm}$ (20 nm bandwidth) and measuring total fluorescence intensity, parallel and perpendicular polarized light at $528 \mathrm{~nm}(20 \mathrm{~nm}$ bandwidth). G-factor (the instrument calibration factor) was calculated from wells with 10 nM pssRNA-2 alone. The data at different NS3 concentrations ([S]) were fitted to the quadratic equation: $f=A^{\prime}\left\{\left(K_{d}+[S]+10\right) / 2-s q r t\left[\left(K_{d}+\right.\right.\right.$ $\left.\left.[S]+10)^{2} / 4-[S]^{\prime} 10\right]\right\}$, where the "A" represents the amplitude of the FP value change and 10 is the concentration of pssRNA-2 $(10 \mathrm{nM})$ and $\mathrm{K}_{\mathrm{d}}$ is the dissociation constant of the NS3-RNA binding complex.

\section{Virus rescue and titration}

The virus was rescued as previously described $[20,45,46]$. Briefly, $2 \mu \mathrm{g}$ of WT CSFV cDNA clone and its variants containing two sets of mutations were transfected into PK-15 cells using Lipofectamine 3000 (Invitrogen), respectively. After incubation at $37^{\circ} \mathrm{C}$ for $72 \mathrm{~h}$, the virus production was monitored by indirect immunofluorescence assay (IFA) using anti-NS3 rabbit polyclonal antibody as primary antibody [20] and an Alexa Fluor 488-conjugated secondary antibody (goat anti-rabbit lgG, Invitrogen). The cultured supernatant was harvested and clarified by centrifugation for virus titration. The virus titers were calculated by IF staining [20] with anti-NS3 antibody in 96- 
well plates using the Reed-Muench method [32] and expressed as tissue culture infectious doses (50\% endpoint, $\mathrm{TCID}_{50}$ ) per milliliter.

\section{RT-qPCR}

Viral RNA copy numbers were determined using a reverse transcription-quantitative PCR (RT-qPCR) [19, 30]. PK-15 cell monolayers in 24-well plates were infected with the virus at an MOI of 0.001. Total RNA was extracted from the infected cells at 6, 12 and 24 hpi using a TaKaRa MiniBEST Universal RNA Extraction Kit (TaKaRa) and 500 ng of total RNA was reverse-transcribed using a ReverTra Ace qPCR RT Kit (TaKaRa) with a specific primer (5'TAGCCTAATAGTGGGCCTCTG $-3^{\prime}$ ). Then the cDNA transcribed from 50 ng of total RNA was analyzed by qPCR using a THUNDERBIRD Probe qPCR Mix kit (TaKaRa) with a 5'-FAM labeled probe (5'TCAGGTCGTACTCCCATCACGTGGTGTGA-3') and the primers CSF-F174 (5'-ACAGGACAGTCGTCAGTAGTTC3')/CSF-R345 (5'-TAGCCTAATAGTGGGCCTCTG-3'). The quantitative cDNA containing the 5'UTR of CSFV genome was used as a standard for qPCR. The cycling parameters consisted of denaturation at $95^{\circ} \mathrm{C}$ for $60 \mathrm{~s}$, followed by 40 amplification cycles $\left(95^{\circ} \mathrm{C}\right.$ for $15 \mathrm{~s}$ and $60^{\circ} \mathrm{C}$ for $60 \mathrm{~s}$ ) and the fluorescent signals were detected by a BioRad CFX connect Real-time PCR detection System. The RNA copy numbers ( $\left.\log _{10} \mathrm{copies} / \mu \mathrm{g}\right)$ were calculated from 3 independent experiments.

\section{Statistical analysis}

Statistical analysis of the data was performed using the Student's $t$ test. A $p$-value of less than 0.05 was considered significant.

\section{Results}

\section{Expression and purification of NS3 and its mutants}

To investigate the effect of amino acid substitutions in the positively charged surface patch of NS3 on enzyme activities, the expression plasmid harboring single or simultaneous substitution of four basic residues $(H 24, \mathrm{R} 50$, K74 and K94) (Fig. 1) was constructed using the plasmid pET28a-NS3/NS4A ${ }^{\text {PCS }}$ as a template [49], respectively. These basic amino acids are highly conserved in Pestivirus NS3 (Fig. 1A, bottom). The four basic amino acids were simultaneously substituted to alanine (A) or aspartic acid (D) in NS3/NS4A ${ }^{\text {PCS }}$ surface patch to generate the corresponding mutant, Quad_A or Quad_D. The truncated NS3 (NS3Hel) and the mutant NS3/K232A were used as control for enzymatic assay [18, 42]. The recombinant proteins were expressed in E. coli and the purified proteins were analyzed by SDS-PAGE. Data showed that the purified proteins were successfully prepared (Fig. 1C).

\section{The positively charged surface patch modulates the helicase activity of NS3 independent of its ATPase activity in vitro}

To assess the effect of basic amino acid substitutions in the NS3/NS4A ${ }^{\mathrm{PCS}}$ surface patch on the helicase/ATPase activities of NS3, we firstly measured the ATPase activities of WT NS3 and its mutants in vitro. ATP hydrolyses of NS3 (WT) and its mutants (for simplicity, hereinafter collectively referred to as mutated amino acid symbol) were determined under steady-state conditions and the data were fit to the Michaelis-Menten equation $\left(v=V_{\text {max }}[S] / K_{M^{+}}\right.$ [S]) to calculate apparent $K_{M}\left(K_{M}{ }^{\text {app }}\right)$ and $k_{\text {cat }}$ by non-linear regression using GraphPad Prism software. Data 
showed that the mutants containing the conserved residue substitutions of NS3 basic patch had $K_{M}$ app (ATP) values in the range 35-56 $\mu \mathrm{M}$ and $k_{c a t}$ values in the range of 4.4-5.5 $\mathrm{sec}^{-1}$. As a control, the $K_{M}$ app (ATP) of WT was $42.2 \pm 2.4 \mu \mathrm{M}$ and $k_{\text {cat }}$ was $5.1 \pm 0.1 \mathrm{sec}^{-1}$ and that NS3Hel had a $K_{M}$ app (ATP) of $36.6 \pm 3.6 \mu \mathrm{M}$ and $k_{\text {cat }}$ of $4.4 \pm 0.1$ $\sec ^{-1}$ (Fig. 2A and Table 1). These results indicated that perturbation in the positively charged surface patch of NS3 had no influence on its ATPase activity.

We further determined the RNA helicase activities of NS3 and its mutants under a saturating ATP concentration. A partially single stranded RNA (pssRNA) T40:R20 was used as helicase substrate. The percentage of the unwound release strand to the total amount of release strand was calculated based on the fluorescent signals from native polyacrylamide gel electrophoresis (PAGE) to resolve free R20 from T40:R20 complex. WT NS3 unwound 80\% of the R2O under the tested conditions, while the NS3Hel only unwound 15\% of the substrate (Fig. 2B and Table 1). For the mutant NS3/K232A (NC), an extremely low unwinding activity was observed (Fig. 2B, 6\% unwound). In the Set 1 , the R50A, K74A and K94A mutants unwound $71 \%, 86 \%$ and $64 \%$ substrate, respectively. The mutants $\mathrm{H} 24 \mathrm{~A}$ and Quad_A exhibited a significantly decreased unwinding activity (Fig. 2B, 50\% and 54\% unwound) compared to WT NS3. In the Set 2, the mutant K74D unwound 71\% substrate and unwinding activities of the remaining mutants significantly decreased compared to WT NS3 (Fig. 2B; 47-64\% unwound). The mutant Quad_D had the lowest helicase activity (Fig. 2B). These observations collectively suggested that the basic residues in NS3 surface patch modulated the helicase activity in vitro.

\section{The basic residues in the surface patch regulate synergistically the RNA-binding ability of NS3}

To further understand the regulatory mechanism of the charged patch in NS3 protease domain for RNA unwinding activity, we assessed the RNA-binding ability of NS3 and its mutants. We hypothesized that the 5'-region of substrate release strand resides in the back of NS3 and allows itself to bind the charged patch on protease domain. We prepared another pssRNA-2 by annealing the T40 template strand and a 5'-FAM labeled 33-mer release strand (R33). A FP-based RNA binding assay $[28,31]$ identified that the apparent equilibrium dissociation constant $\left(K_{d}\right)$ of NS3 was $30.4 \pm 4.3 \mathrm{nM}$ and that the mutant NS3/K232A (NC) exhibited a similar RNA-binding ability of NS3 with a $K_{d}$ of $39.4 \pm 9.9 \mathrm{nM}$ (Fig. 3 and Table 1 ). The truncated mutant NS3Hel hardly bound RNA substrate and the value of $K_{d}$ could not be detected under the tested condition (Fig. 3 and Table 1). In the Set 1, the mutant Quad_A exhibited significantly increased $K_{d}$ values with $84 \mathrm{nM}$, but the $K_{d}$ values of remaining mutants ranged from 24 to $39 \mathrm{nM}$, a similar Kd of NS3 (Fig. 3 and Table 1). In the Set 2, the mutant Quad_D showed $K_{d}$ values of 160 nM and the remaining mutants had $K_{d}$ values in the range of 27-58 nM (Fig. 3 and Table 1). Compared to Quad_A, Quad_D exhibited significantly decreased RNA-binding ability. These results suggested that the four basic residues in the protease domain regulated the helicase activity by synergistically affecting the RNA-binding ability of NS3.

\section{The positively charged surface patch of NS3 plays an important role in regulating the CSFV production}

To investigate the role of the positively charged surface patch on NS3 for infectious virus production, we introduced the various mutations into an infectious full-length cDNA clone of CSFV Shimen strain, $\mathrm{PSPT}_{\square} / \mathrm{SM}_{\text {[20], }}$ respectively. The full-length cDNA construct was transfected into PK-15 cells to rescue infectious CSFV. The lowercase ' $v$ ' as the prefix of each construct is referred to infectious CSFV. The recovery of infectious CSFV was detected by IFA with an anti-NS3 antibody at $72 \mathrm{~h}$ post transfection. Data showed that PK-15 cells transfected with the construct harboring H24A, R50A,K74A, H24D, R50D or K74D mutation were positive for viral antigen detection. 
No viral antigen was detected in PK-15 cells transfected with infectious cDNA clone containing K94A, Quad_A, K94D or Quad_D mutation (Fig. 4A and Table 1).

Next, we detected the titers of rescued CSFVs. Compared to the vWT, the mutant vK74A had a similar virus titer. However, the virus titer of the mutant vH24A, vR50A, vH24D, vR50D or vK74D significantly decreased (Fig.

4A). Consistent with viral antigen detection, the infectious CSFV was not rescued from the vK94A, vQuad_A, vK94D or Quad_D construct (Fig. 4A and Table 1). Viral RNA copy numbers in infected cells were determined using RTqPCR $[19,30]$. Compared to the vWT, the viral RNA copy numbers significantly decreased from the mutants vR50A (6 to $24 \mathrm{hpi}$ ), vR50D and vK74D (12 and $24 \mathrm{hpi}$ ), or vH24A and vH24D (24 hpi). Expectedly, CSFV genomic RNA of the mutant vK74A exhibited a similar level to vWT (Fig. 4B). The alteration of RNA copy numbers was consistent with that of virus titers. These results suggested that the positively charged surface patch of CSFV NS3 played an important role in regulating infectious virus production by modulating viral RNA replication.

\section{Discussion}

Although NS3 in the members of Flaviviridae family is a natural fusion protein with two separable enzymatic modules, the N-terminal protease and C-terminal NTPase/helicase of the protein are functionally coupled. The Pestivirus NS3 protease domain catalyzes cleavage of host and viral proteins and is essential for the process of viral RNA replication $[36,49]$. The protease domain is required for RNA unwinding by NS3 helicase and greatly enhances the binding ability of NS3 to RNA. Intermolecular electrostatics in HCV NS3 plays an important role in this process [3]. For West Nile virus NS3, this crosstalk of protease and helicase modules harbors an auto-regulation function through the interactions between these two modules [7]. Perturbation into the CSFV NS3 protease-helicase interface by point mutations impaired both the helicase activities in vitro and virus production in vivo [49].

It has been widely reported that the NS3 protease domain stimulated the RNA unwinding activity of its helicase in the members of Flaviviridae family [1, 23, 39, 43, 44, 48, 49]. In HCV, NS3Hel exhibited greatly decreased both helicase activity and RNA-binding ability compared to the NS3fl $[3,11]$. The electrostatics and allosteric contribution from the interaction interface between CSFV NS3 helicase and protease modules play an important role in the enhanced RNA-binding ability of NS3 by the protease domain [49]. Here, we further addressed the effect of residue substitutions in the basic patch on the infectious virus production. Interestingly, no direct correlation was observed between NS3 helicase activity and virus production. Unexpectedly, when the residue K94 was mutated into alanine or aspartic acid, no infectious CSFV was rescued although the moderate helicase activities were observed in the mutants K94A and K94D in vitro. Previous studies demonstrated that HCV NS3 interacted with NS2 and other viral proteins to form replication complex, which is essential for virus replication and viral particle assembly $[24,34,47]$. Mutations at the interface between the BVDV NS3 protease domain and the NS4Akink region impaired NS3/4A-kink interaction, leading to no longer capable of viral RNA replication [9]. We speculated that K94 on NS3 surface patch is essential for replication complex formation independent of its helicase activity or RNA binding ability. The precise mechanism of action of the residue K94 on NS3 surface patch needs to be further addressed. Among the remaining mutants harboring single residue substitution, the virus titer was to a certain extent related to the helicase activity and RNA-binding ability of NS3. The simultaneous fourresidue substitution (Quad_A or Quad_D) resulted in significantly decreased RNA-binding ability and helicase activity of NS3 in vitro. Expectedly, no infectious virus could be rescued from the full-length cDNA clone harboring the Quad_A or Quad_D mutant. Collectively, our results suggested that the positively charged surface patch on 
pestivirus protease module plays an important role in modulating NS3 helicase activity and virus production. These findings contribute to the understanding of pestivirus NS3 functional regulation and the design of novel antiviral strategies.

\section{Declarations}

\section{Conflict of interest statement}

The authors declare that they have no competing financial interests.

\section{Acknowledgements}

This study was supported by the National Key Research and Development Program of China (2018YFD0500104), the National Natural Science Foundation of China (31570152 \& 31670154)

\section{References}

1. Aydin C, Mukherjee S, Hanson AM, Frick DN, Schiffer CA (2013) The interdomain interface in bifunctional enzyme protein 3/4A (NS3/4A) regulates protease and helicase activities. Protein Sci 22:1786-1798

2. Becher P, Orlich M, Thiel HJ (1998) Complete genomic sequence of border disease virus, a pestivirus from sheep. J Virol 72:5165-5173

3. Beran RK, Serebrov V, Pyle AM (2007) The serine protease domain of hepatitis C viral NS3 activates RNA helicase activity by promoting the binding of RNA substrate. J Bio Chem 282:34913-34920

4. Beran RK, Pyle AM (2008) Hepatitis C viral NS3-4A protease activity is enhanced by the NS3 helicase. J Bio Chem 283:29929-29937

5. Bintintan I, Meyers G (2010) A new type of signal peptidase cleavage site identified in an RNA virus polyprotein. J Bio Chem 285:8572-8584

6. Bradford MM (1976) A rapid and sensitive method for the quantitation of microgram quantities of protein utilizing the principle of protein-dye binding. Anal Biochem 72:248-254

7. Chernov AV, Shiryaev SA, Aleshin AE, Ratnikov BI, Smith JW, Liddington RC, Strongin AY (2008) The twocomponent NS2B-NS3 proteinase represses DNA unwinding activity of the West Nile virus NS3 helicase. J Bio Chem 283:17270-17278

8. Colett MS, Larson R, Gold C, Strick D, Anderson DK, Purchio AF (1988) Molecular cloning and nucleotide sequence of the pestivirus bovine viral diarrhea virus. Virology 165:191-199

9. Dubrau D, Tortorici MA, Rey FA, Tautz N (2017) A positive-strand RNA virus uses alternative protein-protein interactions within a viral protease/cofactor complex to switch between RNA replication and virion morphogenesis. PLoS pathogens 13:e1006134

10. Edwards S, Fukusho A, Lefevre PC, Lipowski A, Pejsak Z, Roehe P, Westergaard J (2000) Classical swine fever: the global situation. Vet Microbiol 73:103-119

11. Frick DN, Rypma RS, Lam AMI, Gu BH (2004) The nonstructural protein 3 protease/helicase requires an intact protease domain to unwind duplex RNA efficiently. J Bio Chem 279:1269-1280

12. Gladue DP, Holinka LG, Largo E, Fernandez Sainz I, Carrillo C, O'Donnell V, Baker-Branstetter R, Lu Z, Ambroggio X, Risatti GR, Nieva JL, Borca MV (2012) Classical swine fever virus p7 protein is a viroporin involved in 
virulence in swine. J Virol 86:6778-6791

13. Gu B, Liu C, Lin-Goerke J, Maley DR, Gutshall LL, Feltenberger CA, Del Vecchio AM (2000) The RNA helicase and nucleotide triphosphatase activities of the bovine viral diarrhea virus NS3 protein are essential for viral replication. J Virol 74:1794-1800

14. Harada T, Tautz N, Thiel HJ (2000) E2-p7 region of the bovine viral diarrhea virus polyprotein: Processing and functional studies. J Virol 74:9498-9506

15. Houe H (1999) Epidemiological features and economical importance of bovine virus diarrhoea virus (BVDV) infections. Vet Microbiol 64:89-107

16. Lackner T, Muller A, Pankraz A, Becher P, Thiel HJ, Gorbalenya AE, Tautz N (2004) Temporal modulation of an autoprotease is crucial for replication and pathogenicity of an RNA virus. J Virol 78:10765-10775

17. Lamp B, Riedel C, Roman-Sosa G, Heimann M, Jacobi S, Becher P, Thiel HJ, Rumenapf T (2011) Biosynthesis of classical swine fever virus nonstructural proteins. J Virol 85:3607-3620

18. Lamp B, Riedel C, Wentz E, Tortorici MA, Rumenapf T (2013) Autocatalytic cleavage within classical swine fever virus NS3 leads to a functional separation of protease and helicase. J Virol 87:11872-11883

19. Li L, Wu R, Zheng F, Zhao C, Pan Z (2015) The N-terminus of classical swine fever virus (CSFV) nonstructural protein 2 modulates viral genome RNA replication. Virus Res 210:90-99

20. Li L, Pang H, Wu R, Zhang Y, Tan Y, Pan Z (2016) Development of a novel single-step reverse genetics system for the generation of classical swine fever virus. Arch Virol 161:1831-1838

21. Lindenbach BD, Thiel H-J, Rice CM (2007) Flaviviridae: the viruses and their replication. In Knipe DM, Howley PM (ed), Fields virology, fifthed, vol 1 Lippincott, Williams \& Wilkins, Philadelphia, PA:1101-1152

22. Lu G, Gong P (2013) Crystal Structure of the full-length Japanese encephalitis virus NS5 reveals a conserved methyltransferase-polymerase interface. PLoS pathogens 9:e1003549

23. Luo D, Wei N, Doan DN, Paradkar PN, Chong Y, Davidson AD, Kotaka M, Lescar J, Vasudevan SG (2010) Flexibility between the protease and helicase domains of the dengue virus NS3 protein conferred by the linker region and its functional implications. J Bio Chem 285:18817-18827

24. Ma Y, Anantpadma M, Timpe JM, Shanmugam S, Singh SM, Lemon SM, Yi M (2011) Hepatitis C virus NS2 protein serves as a scaffold for virus assembly by interacting with both structural and nonstructural proteins. J Virol 85:86-97

25. Meyers G, Rumenapf T, Thiel HJ (1989) Molecular cloning and nucleotide sequence of the genome of hog cholera virus. Virology 171:555-567

26. Morgenstern KA, Landro JA, Hsiao K, Lin C, Gu Y, Su MS, Thomson JA (1997) Polynucleotide modulation of the protease, nucleoside triphosphatase, and helicase activities of a hepatitis $C$ virus NS3-NS4A complex isolated from transfected COS cells. J Virol 71:3767-3775

27. Moulin HR, Seuberlich T, Bauhofer O, Bennett LC, Tratschin JD, Hofmann MA, Ruggli N (2007) Nonstructural proteins NS2-3 and NS4A of classical swine fever virus: essential features for infectious particle formation. Virology 365:376-389

28. Mukherjee S, Hanson AM, Shadrick WR, Ndjomou J, Sweeney NL, Hernandez JJ, Bartczak D, Li K, Frankowski KJ, Heck JA, Arnold LA, Schoenen FJ, Frick DN (2012) Identification and analysis of hepatitis C virus NS3 helicase inhibitors using nucleic acid binding assays. Nucleic acids Res 40:8607-8621

29. Pang PS, Jankowsky E, Planet PJ, Pyle AM (2002) The hepatitis C viral NS3 protein is a processive DNA helicase with cofactor enhanced RNA unwinding. The EMBO journal 21:1168-1176

Page 9/15 
30. Pei J, Zhao M, Ye Z, Gou H, Wang J, Yi L, Dong X, Liu W, Luo Y, Liao M, Chen J (2014) Autophagy enhances the replication of classical swine fever virus in vitro. Autophagy 10:93-110

31. Provazzi PJ, Mukherjee S, Hanson AM, Nogueira ML, Carneiro BM, Frick DN, Rahal P (2015) Analysis of the Enzymatic Activity of an NS3 Helicase Genotype 3a Variant Sequence Obtained from a Relapse Patient. PloS one 10:e0144638

32. Reed LJ, Muench H (1938) A simple method of estimating fifty per cent endpoints. Am J Epidem 27:493-497

33. Sheng C, Xiao M, Geng X, Liu J, Wang Y, Gu F (2007) Characterization of interaction of classical swine fever virus NS3 helicase with 3' untranslated region. Virus Res 129:43-53

34. Stapleford KA, Lindenbach BD (2011) Hepatitis C virus NS2 coordinates virus particle assembly through physical interactions with the E1-E2 glycoprotein and NS3-NS4A enzyme complexes. J Virol 85:1706-1717

35. Stoscheck CM (1990) Quantitation of protein. Methods in enzymology 182:50-68

36. Tautz N, Kaiser A, Thiel HJ (2000) NS3 serine protease of bovine viral diarrhea virus: characterization of active site residues, NS4A cofactor domain, and protease-cofactor interactions. Virology 273:351-363

37. Tautz N, Tews BA, Meyers G (2015) The Molecular Biology of Pestiviruses. Adv Virus Res 93:47-160

38. Thiel HJ, Stark R, Weiland E, Rumenapf T, Meyers G (1991) Hog cholera virus: molecular composition of virions from a pestivirus. J Virol 65:4705-4712

39. Tortorici MA, Duquerroy S, Kwok J, Vonrhein C, Perez J, Lamp B, Bricogne G, Rumenapf T, Vachette P, Rey FA (2015) X-ray structure of the pestivirus NS3 helicase and its conformation in solution. J Virol 89:4356-4371

40. Tratschin JD, Moser C, Ruggli N, Hofmann MA (1998) Classical swine fever virus leader proteinase Npro is not required for viral replication in cell culture. J Virol 72:7681-7684

41. Weiland F, Weiland E, Unger G, Saalmuller A, Thiel HJ (1999) Localization of pestiviral envelope proteins E(rns) and E2 at the cell surface and on isolated particles. J Gen Virol 80 ( Pt 5):1157-1165

42. Wen G, Chen C, Luo X, Wang Y, Zhang C, Pan Z (2007) Identification and characterization of the NTPase activity of classical swine fever virus (CSFV) nonstructural protein 3 (NS3) expressed in bacteria. Arch Virol 152:1565-1573

43. Wen G, Xue J, Shen Y, Zhang C, Pan Z (2009) Characterization of classical swine fever virus (CSFV) nonstructural protein 3 (NS3) helicase activity and its modulation by CSFV RNA-dependent RNA polymerase. Virus Res 141:63-70

44. Wu J, Bera AK, Kuhn RJ, Smith JL (2005) Structure of the Flavivirus helicase: implications for catalytic activity, protein interactions, and proteolytic processing. J Virol 79:10268-10277

45. Wu R, Li L, Zhao Y, Tu J, Pan Z (2016) Identification of two amino acids within E2 important for the pathogenicity of chimeric classical swine fever virus. Virus Res 211:79-85

46. Yang ZH, Wu R, Li RW, Li L, Xiong ZL, Zhao HZ, Guo DY, Pan ZS (2012) Chimeric classical swine fever (CSF)Japanese encephalitis (JE) viral replicon as a non-transmissible vaccine candidate against CSF and JE infections. Virus Res 165:61-70

47. Yi M, Ma Y, Yates J, Lemon SM (2007) Compensatory mutations in E1, p7, NS2, and NS3 enhance yields of cell culture-infectious intergenotypic chimeric hepatitis C virus. J Virol 81:629-638

48. Zhang C, Cai Z, Kim YC, Kumar R, Yuan F, Shi PY, Kao C, Luo G (2005) Stimulation of hepatitis C virus (HCV) nonstructural protein 3 (NS3) helicase activity by the NS3 protease domain and by HCV RNA-dependent RNA polymerase. J Virol 79:8687-8697

Page 10/15 
49. Zheng F, Lu G, Li L, Gong P, Pan Z (2017) Uncoupling of Protease trans-Cleavage and Helicase Activities in Pestivirus NS3. J Virol 91:e1904-1917

50. Zheng L, Baumann U, Reymond JL (2004) An efficient one-step site-directed and site-saturation mutagenesis protocol. Nucleic acids Res 32:e115

\section{Table}

Table 1 Effect of the charged amino acid substitutions on the NS3/4A ${ }^{\text {PCS }}$ conformation surface on enzymatic and viral characterizations

\begin{tabular}{|c|c|c|c|c|c|c|c|c|c|}
\hline \multirow[b]{2}{*}{ Construct } & \multirow[b]{2}{*}{$\begin{array}{c}\text { Helicase } \\
\text { activity } \\
(\%)\end{array}$} & \multicolumn{2}{|c|}{ ATPase activity } & \multirow[t]{2}{*}{$\overline{\mathrm{K}_{\mathrm{d}}(\mathrm{nM})}$} & \multirow[b]{2}{*}{$\begin{array}{l}\text { Viral } \\
\text { antigen }\end{array}$} & \multirow{2}{*}{$\begin{array}{l}\text { Virus titer } \\
\quad\left(\log _{10}\right. \\
\left.\text { TCID }_{50} / \mathrm{ml}\right)\end{array}$} & \multicolumn{3}{|c|}{$\begin{array}{c}\text { Viral RNA copies (/ } \mu \text { g total } \\
\text { RNA) }\end{array}$} \\
\hline & & $\begin{array}{c}K_{M} \\
\operatorname{app}(\mu \mathrm{M})\end{array}$ & $k_{\text {cat }}\left(\mathrm{s}^{-1}\right)$ & & & & 6 hpi & 12 hpi & $24 \mathrm{hpi}$ \\
\hline WT NS3 & $79.5 \pm 9.3$ & $42.2 \pm 2.4$ & $5.1 \pm 0.1$ & $30.4 \pm 4.3$ & + & $7.4 \pm 0.3$ & $2.9 \pm 0.5$ & $4.1 \pm 0.5$ & $5.9 \pm 0.4$ \\
\hline NS3Hel & $15.1 \pm 4.9$ & $36.6 \pm 3.6$ & $4.4 \pm 0.1$ & - & - & ND & & & \\
\hline $\mathrm{NC}$ & $5.7 \pm 0.8$ & ND & ND & $39.4 \pm 9.9$ & - & ND & & & \\
\hline H24A & $50.4 \pm 10.2$ & $56.3 \pm 3.2$ & $4.8 \pm 0.1$ & $23.7 \pm 7.9$ & + & $6.4 \pm 0.4$ & $3.1 \pm 0.1$ & $4.0 \pm 0.1$ & $5.0 \pm 0.1$ \\
\hline R50A & $71.5 \pm 6.5$ & $40.5 \pm 2.8$ & $4.8 \pm 0.1$ & $39.3 \pm 8.4$ & + & $5.7 \pm 0.5$ & $2.7 \pm 0.5$ & $3.8 \pm 0.5$ & $5.1 \pm 0.4$ \\
\hline K74A & $85.6 \pm 2.1$ & $38.6 \pm 4.1$ & $5.1 \pm 0.2$ & $26.8 \pm 7.1$ & + & $7.4 \pm 0.4$ & $3.0 \pm 0.6$ & $4.2 \pm 0.6$ & $5.9 \pm 0.6$ \\
\hline K94A & $63.7 \pm 5.0$ & $45.8 \pm 4.2$ & $4.8 \pm 0.1$ & $38.1 \pm 9.7$ & - & ND & & & \\
\hline Quad_A & $54.3 \pm 10.0$ & $35.5 \pm 3.3$ & $5.5 \pm 0.1$ & $84.3 \pm 18.3$ & - & ND & & & \\
\hline H24D & $64.2 \pm 9.6$ & $35.9 \pm 4.5$ & $5.3 \pm 0.2$ & $49.1 \pm 12.4$ & + & $2.6 \pm 0.5$ & $2.6 \pm 0.4$ & $3.6 \pm 0.4$ & $4.0 \pm 0.1$ \\
\hline R50D & $59.5 \pm 9.3$ & $34.6 \pm 3.4$ & $5.5 \pm 0.1$ & $32.0 \pm 9.5$ & + & $5.9 \pm 0.4$ & $2.8 \pm 0.2$ & $3.5 \pm 0.2$ & $4.4 \pm 0.1$ \\
\hline K74D & $70.9 \pm 5.3$ & $42.3 \pm 4.1$ & $4.9 \pm 0.1$ & $57.8 \pm 13.1$ & + & $4.5 \pm 1.1$ & $2.6 \pm 0.6$ & $3.0 \pm 0.3$ & $4.2 \pm 0.3$ \\
\hline K94D & $58.4 \pm 7.3$ & $38.5 \pm 4.0$ & $5.0 \pm 0.1$ & $27.1 \pm 8.8$ & - & ND & & & \\
\hline Quad_D & $47.2 \pm 4.0$ & $41.6 \pm 2.8$ & $5.0 \pm 0.1$ & $160.0 \pm 33.4$ & - & ND & & & \\
\hline
\end{tabular}

\section{Figures}


Fig. 1.

A
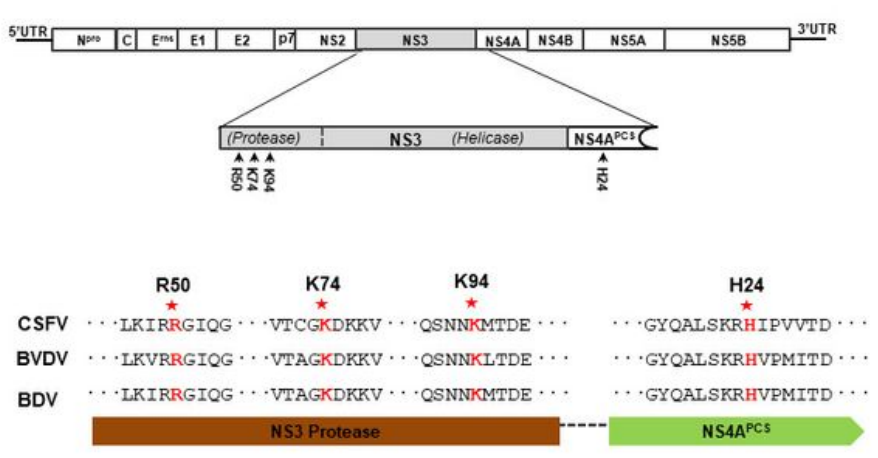

Fig. 1.

B
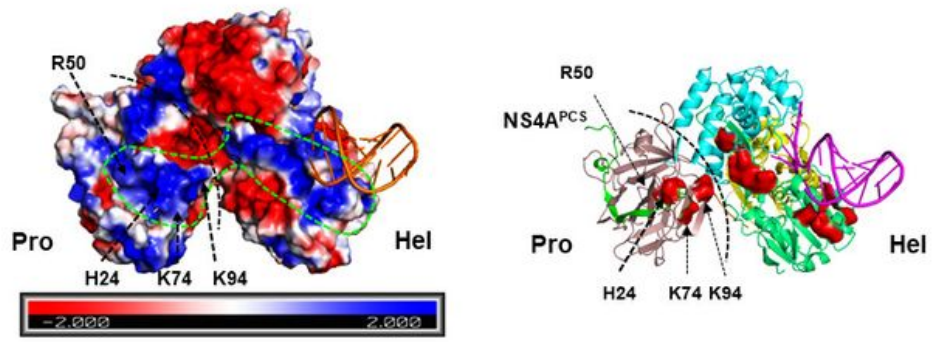

C

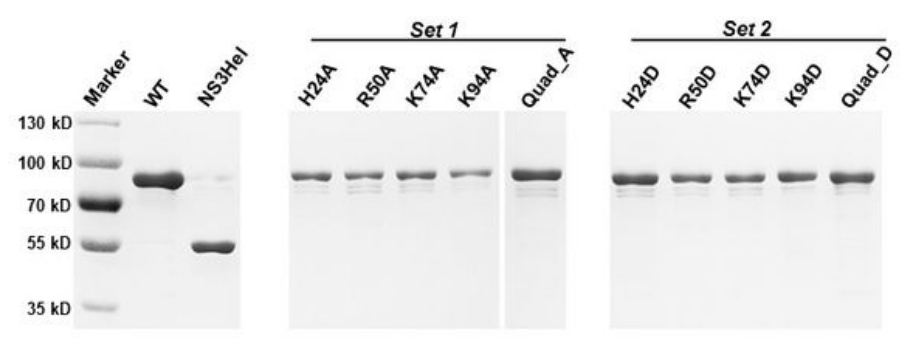

\section{Figure 1}

Expression and purification of WT NS3 and its mutants. (A) The schematic diagram of the CSFV polyprotein and the NS3/NS4APCS construct (top) and the conserved amino acids in the basic surface patch of NS3 with its cofactor NS4APCS (bottom). (B) A continuous surface groove (circled by green dashed lines) with high positive potential (blue) on the three-dimensional structure of the NS3-pssRNA complex (left). Scale bar: $-2 \mathrm{kT} / \mathrm{e}$ to $2 \mathrm{kT} / \mathrm{e}$, where $\mathrm{k}$ is Boltzman constant, and $\mathrm{T}$ is temperature in Kelvin and $\mathrm{e}$ is the charge of an electron. The black discontinuous line is used to distinguish the protease and helicase/ATPase domains of NS3/NS4APCS conformation. The colors in ribbon structure marks as follow (right): red, the basic residue R50, K74, K94 or H24; 
green, NS4APCS; wheat, protease module; yellow, limegreen, cycan, three domains (D1, D2, D3); purple, pssRNA and red, basic residues [49]. (C) Analysis of purified WT NS3 and its mutants by SDS-PAGE.

\section{Fig. 2.}

$\mathbf{A}$

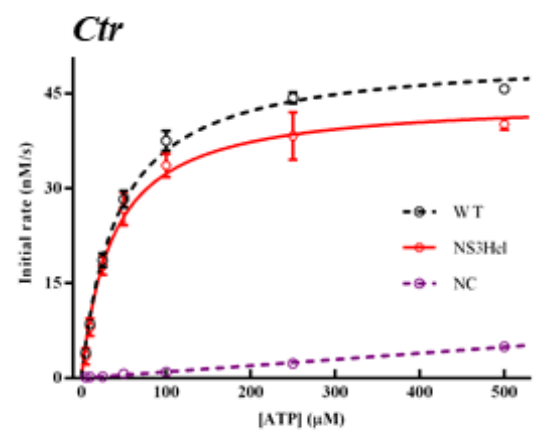

Set 1

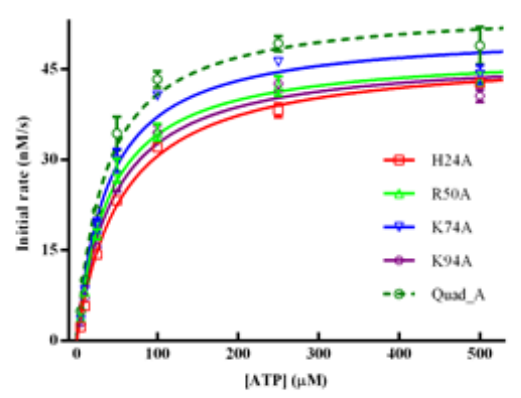

B

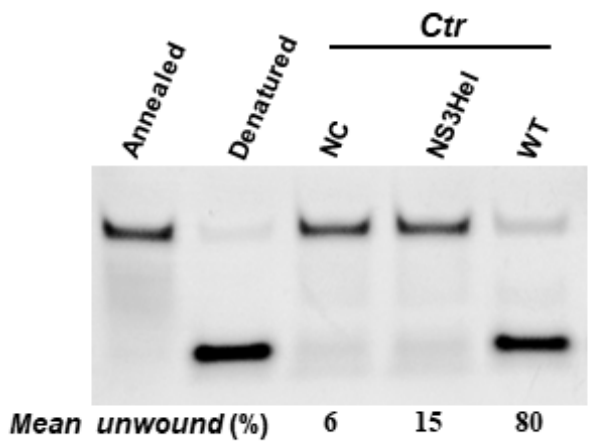

Set 1

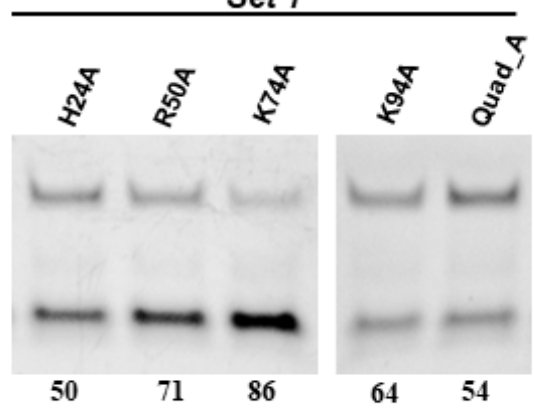

Set 2

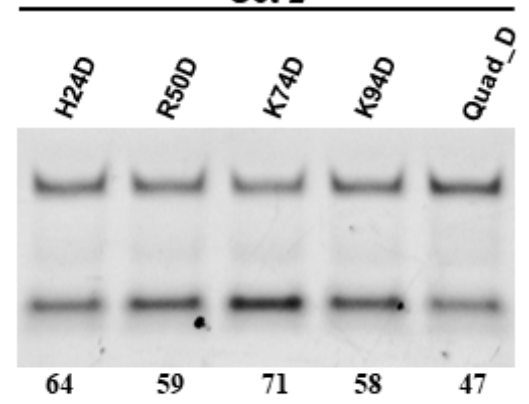

\section{Figure 2}

The ATPase and helicase activities of WT NS3 and its mutants. (A) The ATPase kinetics curves of WT NS3 and its mutants. ATPase activity was measured by a malachite green-based method. The initial reaction rates under different ATP concentrations were fitted to a standard Michaelis-Menten curve (mean $\pm S D ; n=3)$. Ctr represents control. (B) The helicase activity was measured using a T40:R20 pssRNA substrate. Annealed, annealed T40:R20 in the absence of NS3 (upper , the annealed form); Denatured, boiled T40:R20 (lower, the released R20); Ctr, NC, NS3Hel, WT; Set1, the mutants harboring alanine substitution; Set2, the mutants harboring aspartic acid substitution. The measure of helicase activity was carried out 4 times independently and the mean unwound percentages were shown underneath the gels. 
Fig. 3.
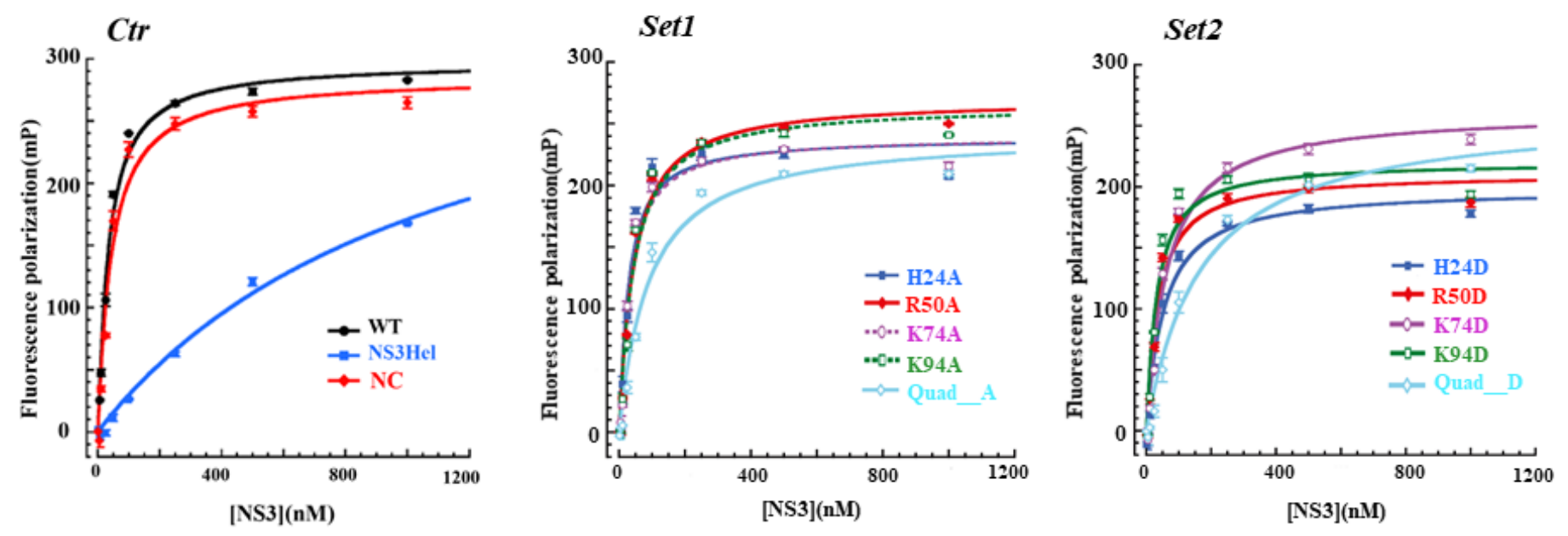

\section{Figure 3}

The RNA-binding abilities of NS3 and its mutants. The RNA-binding abilities of WT NS3 and its mutants were measured using a FP-based assay. A pssRNA-2 annealed by the T40 and a synthesized 5'-FAM labeled 33mer ssRNA (R33) was used in this assay. Data represents the mean value of 3 independent experiments and curves were fitted to the quadratic equation using GraphPad Prism software. 


\section{Fig. 4.}

A

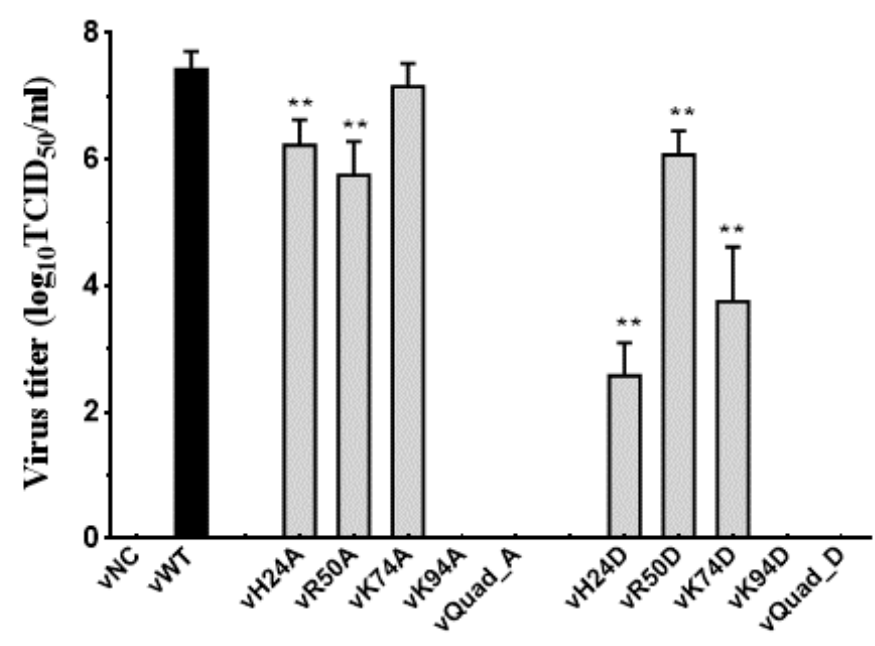

B

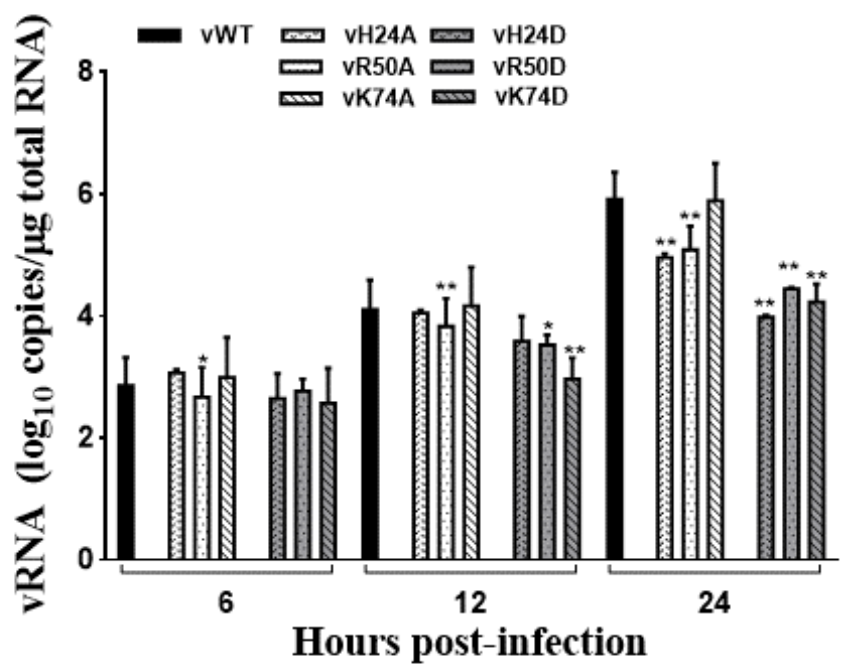

Figure 4

The characteristics of WT CSFV (vWT) and its variants harboring amino acid mutations on NS3/4APCS. (A) Virus titers were measured by IFA with an anti-NS3 antibody and expressed as TCID50/ml. Data represents the mean \pm SD of 4 independent experiments. (B) Viral RNA copy numbers in infected cells. PK-15 cell monolayers were infected with vWT or its variant at a MOI of 0.001, respectively. At 6, 12 and 24 hpi the total RNA was extracted from the infected cells and viral RNA copy numbers were determined by RT-qPCR. The data represent the mean \pm SD of 3 independent experiments. ${ }^{*}, \mathrm{P}<0.05 ;$ **, $\mathrm{P}<0.01$. 